\title{
USE OF DAYLIGHT IN MOSQUES: MEANING AND PRACTICE IN THREE DIFFERENT CASES
}

\author{
H. Ş. AREL \& M. ÖNER \\ Department of Architecture, İmir University, Turkey.
}

\begin{abstract}
Since the emergence of the first cultures, light has been used in various ways for illuminating indoor spaces with sacred and symbolic meanings. Light has almost the same meaning in every religion: however, in Islam, we distinctly see different notions of light, such as divine light, divine unity and unity of God which sets Islam apart from other religions. Mosques have the most perfect use of light in Islamic architecture. There is no doubt that mosques are sacred spaces that give out an intense sense of the presence of God. Therefore, the use of light in mosques matters for both symbolic and spiritual reasons. We see the most striking and generous use of light particularly in Islamic mosques because light is likened to God, while darkness symbolizes Satan. Therefore, different ways of lighting are employed in order to highlight these notions. In addition to having symbolic and spiritual meanings, the use of light plays a role, in enhancing the decorative and aesthetic aspects of the interior spaces of mosques. Muslims aim at highlighting simplicity, clarity and purity by letting light into the interior of mosques in different ways. Wide spaces with no load-bearing walls, dome windows, colourful windows and grilled windows are used in designing mosques to enhance the symbolic, spiritual and aesthetic sense of the interior. The objective of this study is to present the meaning and practice of light in mosques. Different examples of mosques are investigated here according to the ways in which they let the light inside as well as the atmosphere they create.

Keywords: Islamic architecture, material attributes, mosque design, role of light, structural elements, use of light.
\end{abstract}

\section{INTRODUCTION}

Light is an important factor that reveals the characteristics of an architectural design. It is through light that we can simply determine the quality of any space at a glance. It provides the perception of understanding the space as a whole. Light has the function of improving a living space [1]. When light plays a significant role within the design of a space, it is inevitable to feel the relationship between the meaning and symbolism of light and aesthetics is inevitably felt and when these elements all come together, the quality of a space is enhanced. Throughout history, light has revealed its spiritual and symbolic meanings in almost all religions and belief systems in numerous ways. In addition to being a tool for enhancing visual comfort, it also elicits sacred and spiritual feelings [2]. Although the meaning of light may differ from one culture to another, the presence of light has always been related to spiritual, religious and mystical beliefs.

\subsection{Notions of light throughout history}

In Egyptian mythology, the god $\mathrm{Ra}$ is linked with the sun and is considered the creator of the universe. Ra's eyes, the source of life and creation, represent the sun [2]. Ra was the symbol

This paper is part of the Proceedings of the International Conference on Islamic Heritage Architecture and Art (Islamic Heritage Architecture 2016)

www.witconferences.com 
of the sun and was depicted with a sun disk called Aten which was an aspect of him. Surya, representative of the Sun God in Hinduism, is referred to as the creator of the universe in the Vedas. Arjuna, as Surya's charioteer, is known as the god of sunrise and drives Surya through the heavens [3]. The sacred cow of Hinduism is associated with the sun. Aditi, the cow goddess, first came into being as a divinity of absolute light, which was later depicted as the sun itself giving a kind of milk that symbolizes her nutritious light [4]. Ancient Mesopotamian civilizations portrayed the god Marduk as a bearded man with the rays of the sun emanating from his shoulders. In a similar manner, the Greek sun god Apollo is depicted as wearing a crown adorned with the light of the sun rays [5]. In Christianity, light emerged on the first day of creation in the Bible, Jesus is regarded as the light and Father and Christ to those who live under his light. According to the Christian belief, if we do not have light, we do not know God. Those who do know God and who walk with Him are of the light and walk in the light. They are made companions of God's divine nature, 'having escaped the corruption in the world caused by evil desires' (2 Pet. 1:4). In Judaism, God first created the light [1]. A statement in the Torah states that on the first day of creation, God said: 'Let there be light' and there was light [6]. Additionally, light has extremely important meanings in Islam. The use of light has highly significant physical and spiritual implications in relation to heaven and is linked to religious and spiritual power and thus to God himself [7]. According to the Qur'an, one of the first creations of Allah was light. Light is the indication of how divine Allah is and He is mentioned as the light of the heavens and the Earth in the Qur' an (Surah Nur, verse 35). In Surah Nur, Abdullah Ali Yusuf interprets His light, 'the physical light is but a reflection of the true Light in the world of Reality, and that true Light is Allah. We can only think of Allah in terms of our phenomenal experience, and in the phenomenal world, light is the purest thing we know, but physical light has drawbacks incidental to its physical nature... The perfect Light of Allah is free from any such defects.' Along with the notion of God, the Qur'an links light with divine meanings.

Titus Burckhardt states that 'there is no more perfect symbol of the Divine Unity than light' [8]. As shown in Fig. 1, light helps people find the right path and avoid Satan who deceives and misleads them from light into darkness (Al-Baqarah 257). Light, with its metaphysical

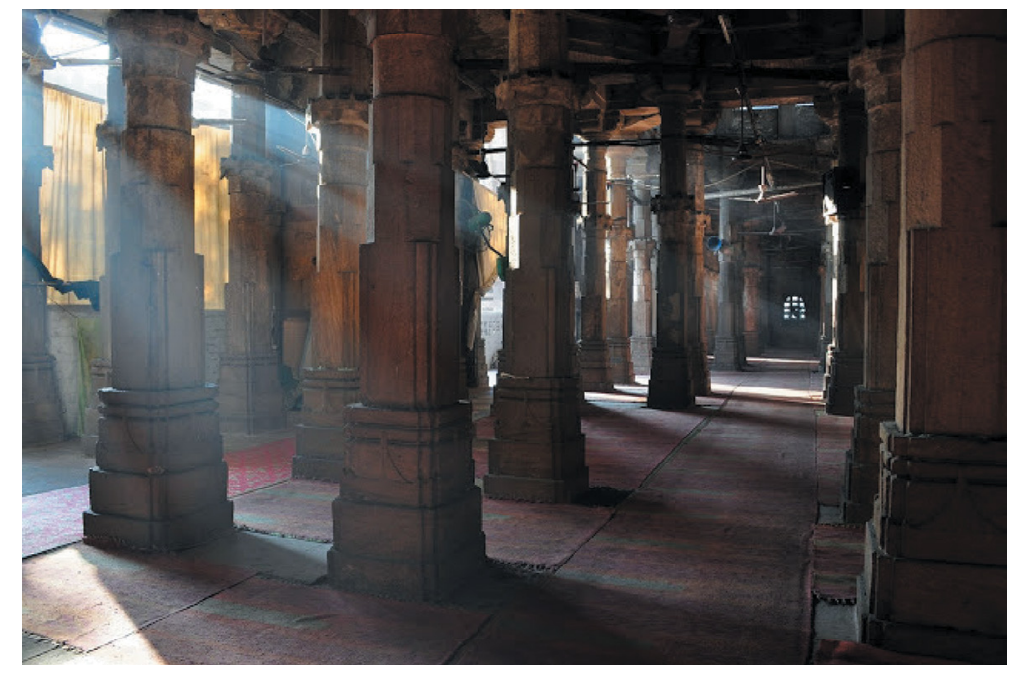

Figure 1: Pir Kamal Mosque, divine light, Ahmedabad. 
existence, is the representational way of purity, goodness and divinity due to its transparency, brightness and contiguity.

\subsection{Lighting in Islamic architecture}

With all these elements in mind, light is the focus of Islamic architecture for reflecting the worldview of Islam. In addition to being used for the illumination of interior spaces, it also provides people with a spiritual and religious vision of Islam as a decorative tool. By means of light, internal spaces, which are formed by man, are connected to exterior space, which is God's physical realm. Thus, light underscores the fragility, relativity and imperfection of man, and the beauty, absoluteness, perfection and infinity of God. Everything depends on Him and His light for its existence in both worlds. Thus, a true believer seeks to apply the transparency of light in the interior because there is nothing to hide regarding his relationship with his creator and his being [9].

\subsection{Meaning of light in a mosque}

In the context of Islamic architecture, and maybe even world architecture, mosques are among the structures which make the most amazing use of light. Well-illuminated mosques are inarguably the most dreamy and peacefully manipulated spaces that guide prayer towards the heavens. As stated by Navaee [10], 'Mosque is the house of light on the one hand, and the light of God on the other. The structure of a mosque should place light in its heart, like the light in the heart of a Muslim.' Light also defines these spaces by revealing their geometry in addition to being used as the representation of the symbolic meanings of existence [11].

With regard to space, mosque geometry is provided via several kinds of mediums such as wide spaces with no load-bearing walls, windows of different sizes and shapes, oculus openings, colored glass and carved screens. Thus, light is supplied inside through peace and harmony and it enhances both the symbolic and the aesthetic values of a mosque. The use of light as a medium for these values emphasizes the building, illuminates the surfaces and creates a dreamy scene for worshippers as there is no representation, picture or statue in the interior spaces of mosques [2]. Concerning the historical background of mosque designs, light has always had the same symbolic meanings, whereas structural restrictions resulted in different approaches to lighting [7]. Despite the fact that light gives life to interior spaces of mosques by enhancing the atmosphere, there has unfortunately, been little discussion made on this topic. By discussing three examples from different cultures, this paper evaluates the kind of structural design approaches that are employed in mosques to create the magnificent impact of light that give people the perception of existence.

\section{THREE DIFFERENT CASES}

\subsection{Selimiye Mosque, Edirne}

According to an inscription over the entrance of the Selimiye Mosque, located in the city of Edirne, construction work started in 1568 and was finished in 1574 by Mimar Sinan during the Ottoman Empire [12]. With a main dome measuring 31 meters in diameter, Selimiye Mosque rises 45 meters above the ground with eight 'elephant foot' pillars that are 3.75 meters in diameter. The upper parts of the pillars are combined with walls that melt the 


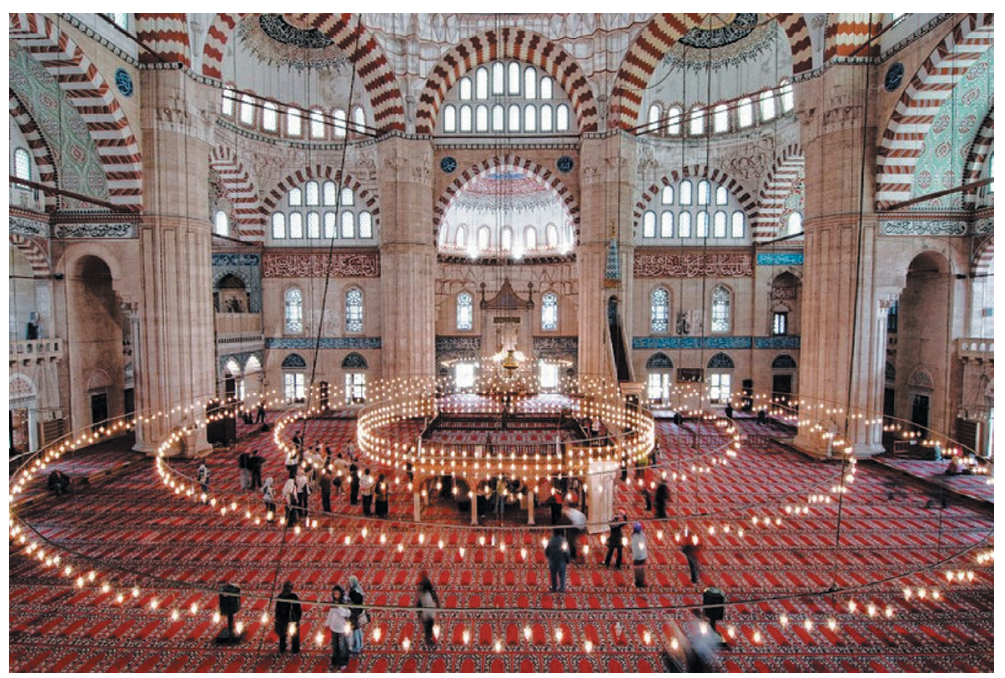

Figure 2: Selimiye Mosque interior, Edirne.

boundary between the piers and walls, thus allowing the structure to create a huge internal space of about $40 \times 45$ meters which emphasizes the unity and oneness of the inner space.

Known as the most perfect of Sinan's masterpieces, Selimiye Mosque is an example of his talent for covering the whole interior using only a single dome. As shown in Fig. 2, the inside of this mosque is superior to that of any other structure on Earth due to its perfect built that distributes light inside equally over every point. Because the structure depends on columns and arches, there are no load-bearing walls, which results in windows that are opened at any height of its walls [7]. The increasing number and size of the windows on both walls and within the dome give the same lighting effect without any feeling of directionality as if it would be impossible for one to guess where the sun is. Illuminance reaches a level of maturity in the Selimiye Mosque with the most generous use of light. The notion of 'being united as a whole' comes into existence in this magnificent structure [13]. The interior space is balanced uniquely in every direction up to the furthest boundaries so that praying worshippers can feel the presence of divine light at any point within the space.

The existence of divine light in the Selimiye Mosque is reinforced with the use of coloured glass and double windows with grates on the outside. There are 384 window openings in total placed at elevations heights from eye level to that of the drum. The windows are arranged on all sides of the mosque in five rows one after the other, and a total of 32 tall and narrow windows pierce all sides of the drum so that light pours down into the mosque. As Fig. 3 shows, daylight flowing down from the dome signifies the light of God under which the worshippers gather. This effect results in peaceful and homogeneous illumination in the deep inner space. As worshippers step into the mosque, they are welcomed with a magnificent sacred light and a feeling of travelling from the inner space to the external world [14]. In addition, Architect Sinan preferred using materials and ornamentation generously in order to enhance the visual pleasure of light and underline the gathering effect of divine light in the Selimiye Mosque. Considering that he used excessive ornamentation in almost none of his masterpieces, these ornamentations cannot be distinguished as elements by themselves because they were used only when needed. The use of marble with its soft white colour contributed to the illumination level of the mosque interior as well. Sinan created smooth illuminated surfaces with 


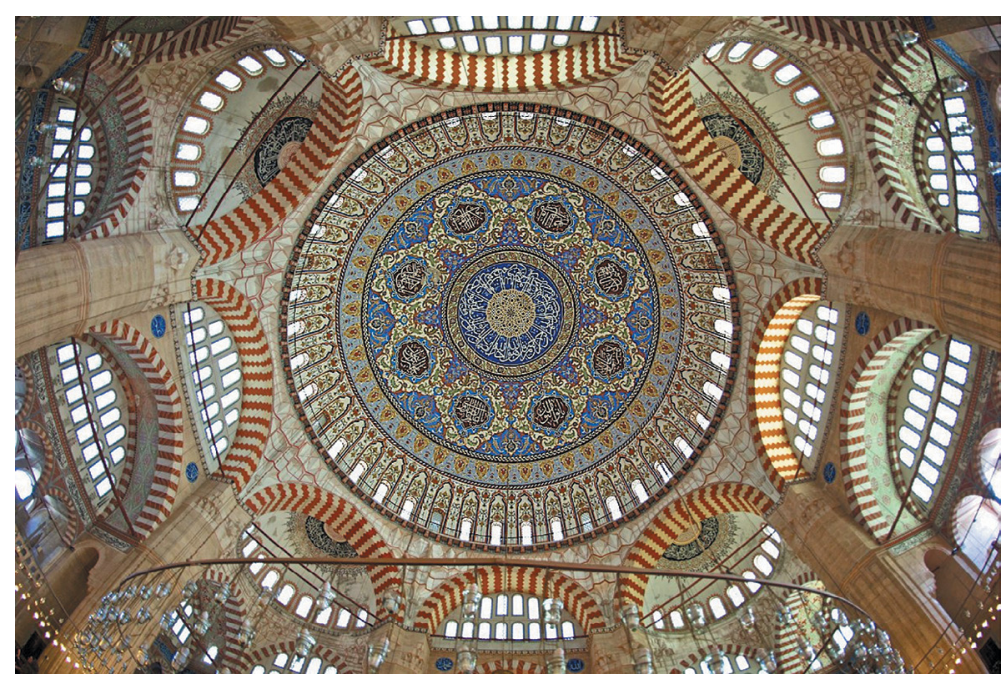

Figure 3: Windows placed around the dome, Selimiye Mosque.

reflective featured materials and tinted colour choices. Thus, he achieved the most successful material preferences in Selimiye Mosque that contribute to the emphasis of divine light and to the gathering of worshippers under a single dome. It is by means of these architectural choices that Sinan created an atmosphere in the Selimiye Mosque that differs both structurally and spiritually from other mosques.

\subsection{The Great Mosque of Cordoba, Cordoba}

There were about 600 mosques in Al-Andalus, the capital city of Medieval Spain, and the Great Mosque of Cordoba built in 785 was the most magnificent mosque. Unlike typical mosque designs, having an arcaded hypostyle hall, the Great Mosque consists of 856 columns, and thus ranks first among sanctuaries. The columns support the double arches made of brick and white stone. These arches represented a new kind of thinking in architecture, which allowed higher ceilings in comparison with the standards [15]. While lower arches are in the form of a horseshoe, the upper arches are semicircular. Also the mosque's richly carved marble mihrab is known as an architectural masterpiece and the best of its kind.

Consequently, the use of light in the Great Mosque of Cordoba shows unique attributes in accordance with the structure. Since the interior space is divided by rows of arches, unlike in other mosques, the spirit of the feeling of the 'One' or the understanding of being 'whole' is obscured by this structure. As Fig. 4 shows, visibility within the interior space at a glance is hindered by a forest of arches. Thus, the communal feeling that mosques ought to have does not exist in the Great Mosque. Rather, here, the structure intends to give worshippers a perception of privacy and of connecting with God directly on their own [16]. Considering the layout, every corner of the mosque is the same, thus providing a feeling of one person not being superior to the other in the presence of God. The concept of infinity is displayed in endlessly repeating architectural elements. Accordingly, the structure of the Great Mosque reflects and enhances the presence of divine light differently. Unlike in the case of the Selimiye Mosque, equally distributed light is not the main concern here. A mysterious atmosphere with lights and shadows is created due to the structural elements inside. The way in which rows of arches smooth out the 


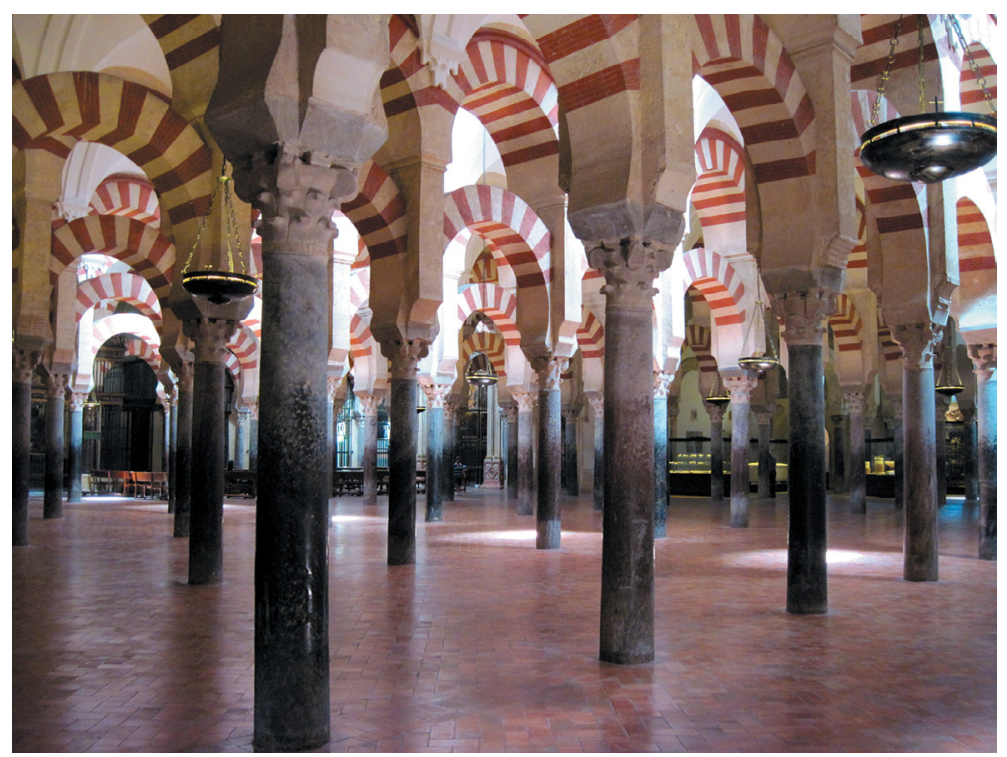

Figure 4: Rows of arches, interior of Great Mosque of Cordoba.

light creates a magnificent play of light inside. The direct sunlight and grilled windows provide a perception of the presence of God. Direct sunlight pouring down from the north end of the mosque is the primary light source. Light streams directly inside the mosque from the north, crashing into the forest of arches and creating inside an atmosphere with perfect depth.

As shown in Fig. 5, windows that are placed on the facades of the Great Mosque let a small amount of light inside and creates a deep atmosphere as it filters through the grilles. Serving mostly decorative purposes, the grilled windows receive filtered light and create a play of light and shadow in the mosque. Thus, light itself turns into a decorative material. Speaking of decorative materials, almost all the wall decorations of the Great Mosque are made from

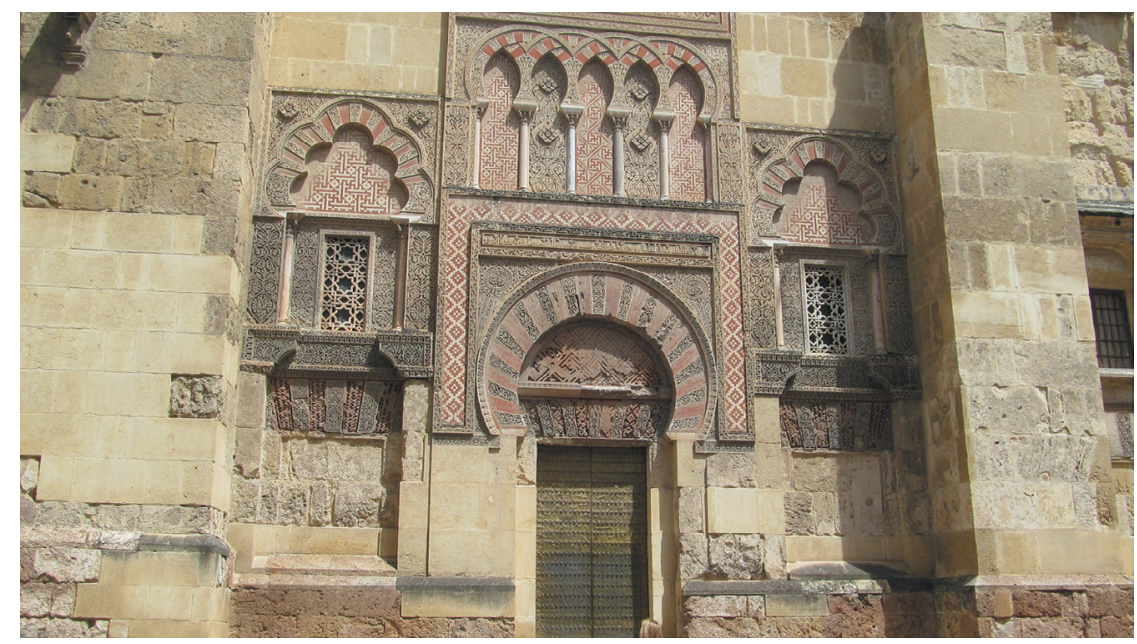

Figure 5: Grilled windows on facade, Great Mosque of Cordoba. 
reflective materials such as tiles and mosaics which reflect the light and hide the walls behind shimmering colour and light. Through the interplay of all these elements, light in the Great Mosque is used not only as a functional part of the structure, but also as a symbolic, spiritual and decorative one.

\subsection{Sheikh Lotfollah Mosque, Isfahan}

Construction work for the Sheikh Lotfollah Mosque, known as one of the masterpieces of Safavid Iranian architecture, started in 1603 and was completed in 1618 by Mohammad-Reza Esfahani during the reign of Shah Abbas [17]. In addition to its fame, due to the excellent and aesthetic use of mosaic tileworks, this mosque also has a unique design approach in comparison with standard mosque designs due to the absence of minarets and courtyard, and it has an entrance that can be reached only by steps [18]. The perception upon entering the main room of the Sheikh Lotfollah Mosque and encountering the beauty of the structure is not possible to describe in words [19]. Possibly the most perfect creation of calligraphy and tilework is seen starkly here. The mosaic tiles of the dome change from glazed to unglazed, which gives the perception of an unstable glow as the sunlight falls onto them [20].

In addition, natural light has been employed beautifully in the interiors of the Sheikh Lotfollah. While the vaulted opening above the entrance is used as the primary light source, the grilled drum windows and similar windows placed along the walls provide the breathtaking atmosphere of the mosque's interior as shown in Fig. 6. It is possible to see the sky through a large vaulted opening from the interior dome, which was placed away from the direction of the Qibla so as to diffuse sunshine on the sanctuary wall and separate it from other parts by employing the power of light [21]. Sixteen windows around the drum, some with a pair of grilles, let the sunlight filter through the dome. In addition, the passage of light effected by the windows, tiles, mosaics and ornamentation reminds worshippers of the divinity in the Sheikh Lotfollah Mosque. The light itself describes the same notion of the presence of God

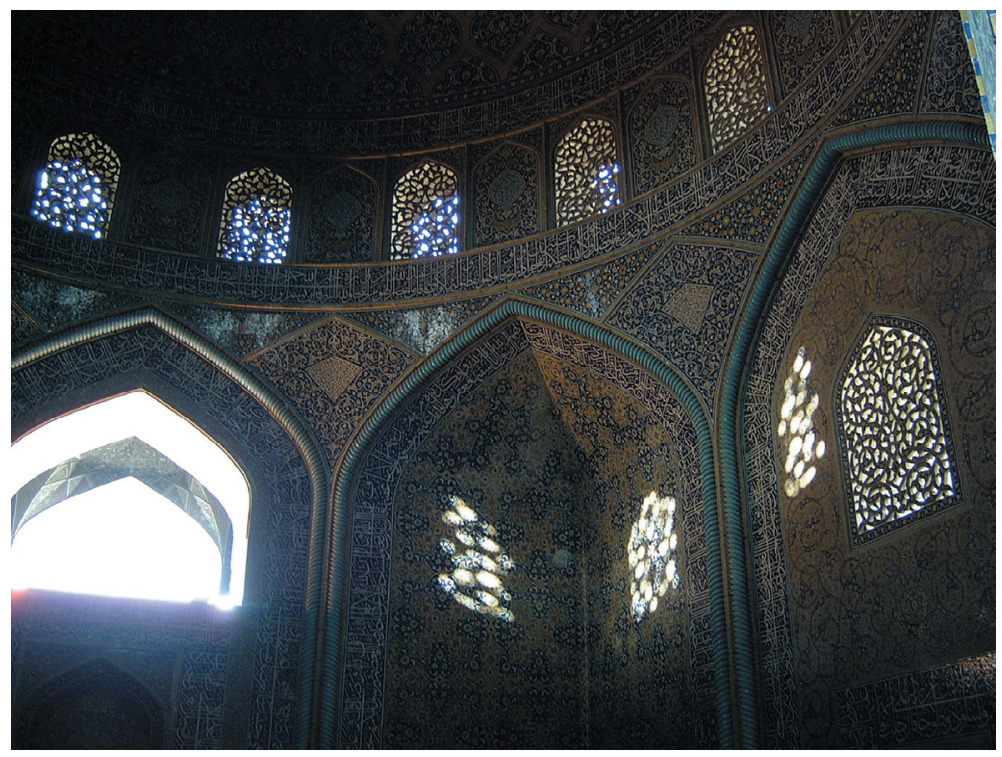

Figure 6: Filtered light through openings of Sheikh Lotfollah, Isfahan. 


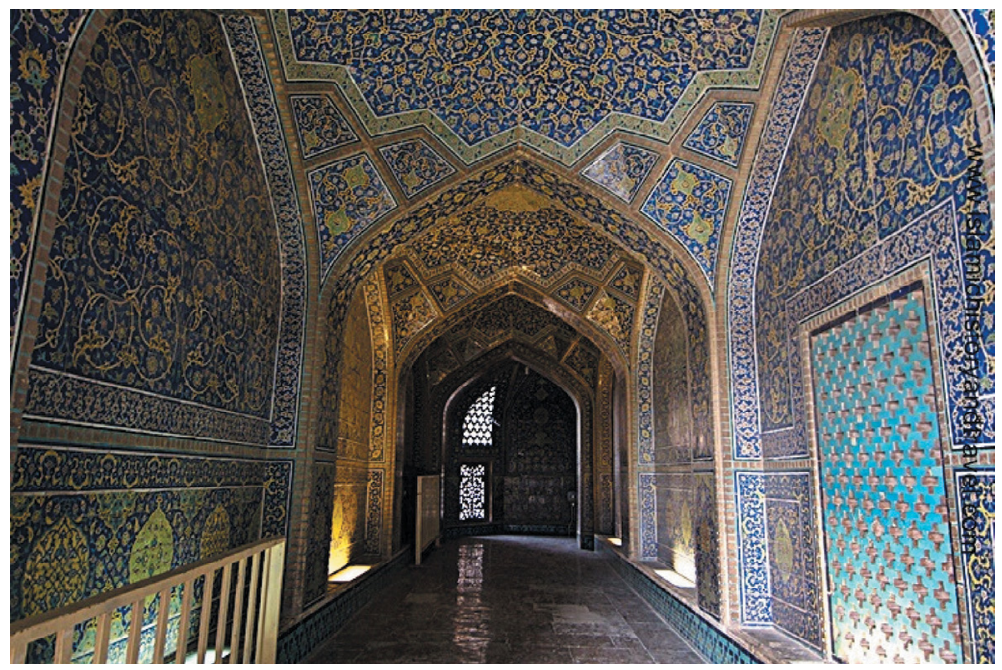

Figure 7: Dark and narrow corridor, Sheikh Lotfollah Mosque.

despite the implementation differing from that of other mosques. As shown in Fig. 7, it is a must for worshippers to climb the five stone steps and as they go through the entrance door, a dark and narrow corridor welcomes them [21]. The radiating light at the end of the corridor, in contrast to the narrow and dark corridor, is the divine light that will soon connect worshippers with the presence of God.

Even though light could have been provided from the north and east directions in this passage of the mosque, it was not preferred as the main concern was the desire for perception using a light hierarchy. It is unlikely that one could have similar experiences in another mosque like the Sheikh Lotfollah, which guides worshippers on the path of God by playing generously with light and materials.

\section{CONCLUSION}

Contrary to the general use of light in architectural design, light plays a much greater role in Islamic architecture and especially mosque architecture, than simply that of defining space. Using light for enhancing symbolic and spiritual values becomes the main concern when designing a mosque. Light is not considered as a regular light source in the interior of mosques; rather it is the presence of God that gathers worshippers under itself. At the same time, differences in practice also arise when light is employed in mosque designs. These distinctions in mosque illumination occur due to structural limitations, which give us perfectly illuminated mosque design examples that are different from each other. While Ottoman mosque designs are inclined to provide the same illumination level at every corner of the huge space due to these architects' advanced expertise in pillar bearing structural systems, the Great Mosque of Cordoba appeared with 856 columns that break the sunlight filtering inside, whereas Sheikh Lotfollah, with its narrow and dark entrance corridor, ends up with divine light at the end of the corridor. Every cultural and structural system comes together through different practices of using light in mosques. One aims at unifying worshippers under the divine light, whereas the other provides privacy to worshippers to connect directly with God. However, the notion of light is always the same: to build a bridge between worshippers and God by emphasizing its mystic, spiritual and symbolic meanings. 


\section{REFERENCES}

[1] Shokrpour, M., Mahboubi, G. \& Fakherian, P., The importance and beauty of light in mosques. Cumhuriyet University Faculty of Science Science Journal, 36(4), pp. 1625-1629, 2015.

[2] Antonakaki, T., Lighting and spatial structure in religious architecture: A comparative study of a Byzantine church and an early Ottoman mosque in the city of Thessaloniki. Proceedings of the 6th International Space Syntax Symposium, Istanbul, 2007.

[3] Jansen, E., The Book of Hindu Imagery, Binkey Kok Publications: the Netherlands, 1993.

[4] Lodrick, D., Sacred Cows, Sacred Places: Origins and Survivals of Animal Homes in India, University of California Press: Berkeley, 1981.

[5] Bram, J.R., 'Sun', Encyclopedia of Religion, MacMillan: New York, pp. 136-139, 1987.

[6] Isaacs, J., Our People: A History of the Jewish People, Kehot Publication Society: New York, 1946-1948.

[7] Erzen, J.N., Reading mosques: Meaning and architecture in Islam. The Journal of Aesthetics and Art Criticism, 69(1), pp. 125-131, 2011.

[8] Burckhardt, T., Art of Islam: Language and Meaning, World of Islam Festival Publishing Company: London, 1976.

[9] Haghighi, M.H.M., Khoshooee, M.A., Noghrekar M.A. \& Bemanian, M.M.R., 'Sustainable concepts in mosques', 5th Symposium on Advances in Science and Technology, Mashhad, 12-17 May 2011.

[10] Navaee, K., Mosque, the icon of perfect man. Collection of Articles: The Conference of Architecture, Past, Present, Future (Arts University of Esfahan), 1, p. 667, 2000.

[11] Nasr, S.H. Íslam Sanatı ve Maneviyatı, Insan Yayınları: Istanbul, 1992.

[12] Atalan, Ö., Ortakoy-Kurucesme, At the beginning of the 20th century. International Periodical for the Languages, Literature and History of Turkish or Turkic, 10(10), pp. 99-132, 2015.

[13] Kuban, D. 'Işık ve Pencere', Mimarbaşı Koca Sinan Yaşadı̆̆ Vakıflar Bankası Genel Müdürlügü: İstanbul, 1988.

[14] Takikawa, M., Hagia Sophia and Sinan's mosques: Structure and decoration in Süleymaniye Mosque and Selimiye Mosque, pp. 103-119, 2015.

[15] Chejne, A.G., Muslim Spain: Its History and Culture, ed. University Of Minnesota Press: Minnesota, p. 364, 1974.

[16] King, R., Divine Constructions: A comparison of the Great Mosque of Cordoba and Notre-Dame-du-Chartres, Boston College University Libraries, Dissertation, 2007.

[17] Clévenot, D., \& Degeorge, G., Splendors of Islam: Architecture, Decoration, and Design, Vendome Press: New York, 2000.

[18] Esmi, A., \& Saremi, H., Mysticism and its impact on Safavid dynasty architecture (Mosque of Sheikh Lotfollah in Isfahan). Research Journal of Environmental and Earth Sciences, 6(6), pp. 333-339, 2014.

[19] Fathalipour, N., The Sheikh Lotfollah Mosque: Consolidating Shi' ism, forming spirituality, and creating the infinite dome. http://stanford.edu/group/avicenna/cgi-bin/wordpress/wp-content/uploads/2014/04/4.1-Sheikh-Lotfallah-Mosque.pdf, pp. 30-35.

[20] Blunt, W., Isfahan, Pearl of Persia, Pallas Athene Ltd: London, 2009.

[21] Jahanshahi, S., The collection of mosque patterns with light hierarchy approach to perception space of architecture (Case Study: Ganjalikhan Mosque and Sheikh Lotfollah Mosque). Journal of Scientific Research and Development, 2(2), pp. 174-180, 2015. 